\title{
De relatie tussen leerstijlen en deelname van studenten aan het vaardigheidsonderwijs
}

\author{
R.J. Nijenhuis, A. Muijtjens, S.J. van Luijk, G.M. Verwijnen, J.J. Rethans
}

\begin{abstract}
Samenvatting
Inleiding: Onderzoek naar de relatie tussen de aanwezigheid van Maastrichtse studenten bij het vaardigheidsonderwijs en hun studieresultaten heeft aangetoond dat meer aanwezigheid leidt tot betere resultaten. Wat de factoren zijn die de aanwezigheid van studenten verklaren is nog niet duidelijk. In de literatuur wordt gedacht aan de leeromgeving en leerstijlen. In deze studie is gekeken in hoeverre de leerstijl van studenten een verklarende factor kan zijn voor aanwezigheid bij vaardigheidsonderwijs.
\end{abstract}

Methode: Met behulp van een leerstijlvragenlijst werden de verschillende scores op de leerstijlkenmerken (ongericht, reproductiegericht, betekenisgericht, toepassingsgericht) van studenten berekend. Deze individuele leerstijlkenmerkscores zijn gecorreleerd met individuele aanwezigheidspercentages.

Resultaten: De resultaten tonen aan dat er positief verband is tussen aanwezigheid en het leerstijlkenmerk 'toepassingsgericht'. Verder is een negatief verband gevonden tussen aanwezigheid en het leerstijlkenmerk 'ongericht'.

Conclusie: Concluderend kunnen wij zeggen dat de aangetoonde relaties in de richting wijzen dat leerstijlen, beter gezegd leerstijlkenmerken, voor een deel de deelname aan vaardigheidsonderwijs kunnen verklaren. (Nijenhuis RJ, Muijtjens A, Luijk SJ van, Verwijnen GM, Rethans JJ. De relatie tussen leerstijlen en deelname van studenten aan het vaardigheidsonderwijs. Tijdschrift voor Medisch Onderwijs 2003;22(6): 283-288.)

\section{Inleiding}

Studieresultaten worden multifactorieel beïnvloed, zoals bijvoorbeeld door studentkenmerken en door leeromgeving. Leeromgeving kan verdeeld worden in twee factoren, namelijk die waar de opleiding invloed op uit kan oefenen en die waar deze geen invloed op heeft. ${ }^{1}$ Een voorbeeld van een factor waar de opleiding invloed op heeft, is de grootte van een onderwijsgroep. Wie de studiegenoten van een student zijn, is niet door de opleiding te beïnvloeden en daarmee een voorbeeld van de andere factor. Studentkenmerken zijn uitvoerig beschreven door Simons. ${ }^{2}$ Hij maakt de volgende indeling:

- Directe kenmerken (voorkennis, leergedrag, beleving van de onderwijssituaties).
- Leerpsychologische kenmerken (leerstijl, leervermogen, motivatie).

- Algemene psychologische kenmerken (de mate van angst, extravert zijn).

- Indirecte kenmerken (leeftijd, ervaring, sekse).

Ook de deelname van studenten aan onderwijsactiviteiten heeft invloed op de studieresultaten. ${ }^{3-6}$ In een cross-sectioneel onderzoek, uitgevoerd aan de Faculteit der Geneeskunde te Maastricht, naar de aanwezigheid van studenten bij vaardigheidstrainingen en anatomiepractica in de eerste twee blokken van elk studiejaar, is de relatie tussen aanwezigheid en toetsprestatie specifiek onderzocht. De belangrijkste conclusie uit deze studie was dat studenten die veel onderwijs 
(zowel training als practica) volgden beter presteerden op tentamens. Uit hetzelfde onderzoek bleek ook dat studenten in de loop van hun studie selectiever worden bij het volgen van onderwijs. Een belangrijke kanttekening bij dit onderzoek is dat de aanwezigheid slechts gedurende de eerste twee blokken van het jaar (drie maanden) geanalyseerd is.

Uit de studie van Van Bokhoven komt naar voren dat de studentkenmerken en de leeromgeving van invloed zijn op de aanwezigheid: het blijkt dat het steeds weer dezelfde studenten zijn die wel of geen trainingen volgen. ${ }^{6}$ Verder kwam uit deze studie ook naar voren dat aanwezigheid bij het vaardigheidsonderwijs leidt tot betere toetsprestaties. Om studenten te kunnen adviseren en de leeromgeving te optimaliseren, oppert zij, moeten er meer gegevens over het studiegedrag van studenten verzameld worden. Om hierover uitspraken te kunnen doen is het van belang inzicht te krijgen in de leerstijl van de student, want dit zal informatie verschaffen over zijn studiegedrag. Momenteel is over de leerstijlen van Maastrichtse studenten geneeskunde nog niet veel bekend. Het doel van deze studie is retrospectief na te gaan wat de relatie is tussen de leerstijl van een student en zijn deelname aan onderwijsactiviteiten, onder de aanname dat aanwezigheid leidt tot betere studieresultaten. Deze relatie wordt onderzocht aan de hand van gegevens over de leerstijl en de deelname aan vaardigheidsonderwijs van een derdejaars groep studenten geneeskunde van de Universiteit van Maastricht.

\section{Materiaal en methoden}

\section{Situatieschets}

Het vaardigheidsonderwijs wordt op het Skillslab als volgt georganiseerd. Elke jaargroep heeft per jaar ongeveer 25 vaar- digheidstrainingen die men vrijwillig kan volgen. Per blok worden zoveel mogelijk blokgerelateerde onderwerpen aangeboden. Elke training wordt gedurende het blok meerdere malen aangeboden om studenten meerdere mogelijkheden tot inschrijving aan te bieden. Er is dus gedurende de opleiding een ruime mate aan keuzevrijheid ten aanzien van het onderwijs dat de student wel of niet wil volgen.

\section{Onderzoekspopulatie}

Omdat dit een retrospectief onderzoek is, is uitgegaan van die groep, waarvan zowel de leerstijlgegegvens als de aanwezigheidsgegevens volledig waren. Dit waren 123 derdejaars studenten. De totale jaargroep bestond uit 202 studenten. Ook van de eerstejaars waren deze gegevens bekend, maar omdat die nog 100\% aanwezig zijn is het onmogelijk om hier naar verbanden te gaan kijken. Van tweede en vierdejaars studenten waren geen gegevens bekend.

\section{Instrument}

Literatuur op het gebied van leerstijlen geeft aan dat een student niet één specifieke leerstijl heeft, maar een leerstijlprofiel op basis van vier leerstijlkenmerken: ongericht, reproductiegericht, betekenisgericht, toepassingsgericht. ${ }^{7}$

Om te bepalen welke leerstijl een student heeft, is er gebruik gemaakt van de vragenlijst van Van Luijk, ${ }^{8}$ die weer een verfijning is van de vragenlijst van Vermunt. ${ }^{7}$ De reden voor het gebruik van deze lijst lag in het feit dat zij een vertaling was naar het probleemgestuurd onderwijs (PGO) van de lijst van Vermunt. De vragenlijst bestond uit 128 stellingen die betrekking hadden op verschillende domeinen, te weten: cognitief, affectief, metacognitief, mentale modellen en leeroriëntaties. Elk van de 128 stellingen behoorde in principe bij één van de vier leer- 
stijlkenmerken (ongericht, reproductiegericht, toepassingsgericht en betekenisgericht). Tabel 1 geeft een overzicht van de verschillende leerstijlkenmerken met bijbehorende kenmerken. In de gebruikte vragenlijst was iedere stelling gekoppeld aan een 5-punts Likertschaal, variërend van 'volledig mee oneens' tot 'volledig mee eens'. De vragenlijst werd op een middag voorafgaand aan een onderwijsgroep uitgedeeld in elke groep en gevraagd werd deze lijst voor aanvang van de volgende bijeenkomst in te vullen. Studenten konden aangeven in hoeverre een stelling bij hun eigen leerstijl behoorde. De vragenlijst van Van Luijk werd gevalideerd door drie inhoudsdeskundigen (Van Luijk, Vermetten en Vermunt). Hen werd gevraagd

Tabel 1. Overzicht van studentkenmerken van leeractiviteiten bij de verschillende leerstijlen.

\begin{tabular}{|c|c|c|c|c|}
\hline \multirow[b]{2}{*}{ Domeinen } & \multicolumn{4}{|c|}{ Leerstijlen } \\
\hline & Ongericht & Reproductiegericht & Betekenisgericht & Toepassingsgericht \\
\hline Cognitief & $\begin{array}{l}\text { - Geen onderscheid } \\
\text { in hoofd en } \\
\text { bijzaken. } \\
\text { - Structureren van } \\
\text { kennis is moeilijk. }\end{array}$ & $\begin{array}{l}\text { - Veel memoriseren } \\
\text { en herhalen. } \\
\text { - Sterk gericht op } \\
\text { feiten en details. }\end{array}$ & $\begin{array}{l}\text { - Proberen strekking } \\
\text { verhaal te begrijpen } \\
\text { - Kunnen zelf studie- } \\
\text { stof goed selecteren }\end{array}$ & $\begin{array}{l}\text { - Proberen studiestof } \\
\text { zo concreet moge- } \\
\text { lijk toe te passen } \\
\text { - Onthouden theorie } \\
\text { gekoppeld aan } \\
\text { praktijk. }\end{array}$ \\
\hline Affectief & $\begin{array}{l}\text { Zijn bang de studie } \\
\text { niet aan te kunnen. }\end{array}$ & $\begin{array}{l}\text { Onzekerheid om } \\
\text { alles te kunnen } \\
\text { onthouden. }\end{array}$ & $\begin{array}{l}\text { Interesse en veel } \\
\text { plezier in de studie. }\end{array}$ & $\begin{array}{l}\text { Interesse speelt een } \\
\text { belangrijke rol. }\end{array}$ \\
\hline Metacognitief & $\begin{array}{l}\text { - Sterk in hun } \\
\text { studeren gericht } \\
\text { op externe sturing. } \\
\text { - Kunnen niet in } \\
\text { grote lijnen denken. }\end{array}$ & $\begin{array}{l}\text { - Beperken zich sterk } \\
\text { tot de examenstof. } \\
\text { - Vragen en zelf- } \\
\text { toetsing erg belang- } \\
\text { rijk voor sturing. }\end{array}$ & $\begin{array}{l}\text { - Zowel extern (door } \\
\text { instructiemaat- } \\
\text { regelen) als intern } \\
\text { gestuurd. } \\
\text { - Gaan na waarom ze } \\
\text { bepaalde zaken niet } \\
\text { begrijpen. }\end{array}$ & $\begin{array}{l}\text { - Regulatie voor het } \\
\text { grootste deel over- } \\
\text { eenkomstig de } \\
\text { betekenisgerichte } \\
\text { leer stijl. } \\
\text { - Kijken doelstelling- } \\
\text { en en studeeraan- } \\
\text { wijzingen altijd door } \\
\text { om te kijken of } \\
\text { doelen bereikt zijn. }\end{array}$ \\
\hline Mentale modellen & $\begin{array}{l}\text { - Willen graag veel } \\
\text { externe sturing. } \\
\text { - Samenwerking } \\
\text { belangrijk. }\end{array}$ & $\begin{array}{l}\text { - Tentamens zijn } \\
\text { erg belangrijk. } \\
\text { - Van buiten leren } \\
\text { en vaak herhalen } \\
\text { is de belangrijkste } \\
\text { studieactiviteit. }\end{array}$ & $\begin{array}{l}\text { - Nadruk op het leg- } \\
\text { gen van verbanden. } \\
\text { - Inzicht belangrijk. }\end{array}$ & $\begin{array}{l}\text { - Doel kennisverwer- } \\
\text { ving en toepassing } \\
\text { in de praktijk. } \\
\text { - Studie nuttiger } \\
\text { naarmate die meer } \\
\text { praktijkgericht is. }\end{array}$ \\
\hline Leeroriëntaties & $\begin{array}{l}\text { Worden de studie } \\
\text { ambivalenter en } \\
\text { krijgen meer twijfels. }\end{array}$ & $\begin{array}{l}\text { Hoog mogelijk punt } \\
\text { halen en certificaten } \\
\text { zijn belangrijk. }\end{array}$ & $\begin{array}{l}\text { Studie wordt gezien } \\
\text { als instrument voor } \\
\text { persoonlijke ontwik- } \\
\text { keling. }\end{array}$ & Willen een vak leren. \\
\hline
\end{tabular}


welke stelling naar hun mening bij welk leerstijlkenmerk hoorde. Alleen als alle drie de beoordelaars de betreffende stelling bij hetzelfde leerstijlkenmerk indeelden, werd deze stelling meegenomen in de analyse.

\section{Aanwezigheidspercentage}

Van de totale derdejaars groep $(n=202)$ zijn de aanwezigheidsgegevens van het vaardigheidsonderwijs verzameld. Aanwezigheidsregistratie vond plaats door de docenten op basis van de inschrijflijsten. Voor elke student is de individuele aanwezigheid berekend. Dit is gedefinieerd in de vorm van het percentage bijgewoonde trainingen van het totaal aantal mogelijk te volgen trainingen (in dit geval 25).

\section{Statistische analyse}

De individuele score per leerstijlkenmerk werd berekend door het gemiddelde te nemen van de betreffende items (minimum 1, maximum 5 op de Likertschaal). Hierna is er een koppeling gemaakt tussen het individuele aanwezigheidspercentage en de individuele score op één van de leerstijlkenmerken, op basis van het identiteitsnummer. Het verband tussen leerstijlkenmerken en aanwezigheid werd berekend met behulp van de Pearson correlatiecoëfficiënt.

\section{Resultaten}

\section{Aanwezigheid}

De aanwezigheid bij vaardigheidstrainingen van de onderzoeksgroep $(n=123)$ varieerde van $0-100 \%$ (gemiddeld $75.2 \%$; mediaan $81.5 \%$ ).

\section{Instrument}

Van de 77 stellingen waarin consensus was bereikt, behoorden 13 stellingen bij het leerstijlkenmerk 'ongericht', 17 stellingen bij 'reproductiegericht', 36 stellingen bij 'betekeningsgericht', 10 stellingen bij 'toepassingsgericht' en 1 stelling was volgens de experts niet in te delen bij één van de leerstijlkenmerken. Uiteindelijk waren er dus 76 bruikbare stellingen. De gemiddelde scores voor de leerstijlkenmerken waren respectievelijk voor 'ongericht' 2.7 $(\mathrm{SD} \pm 0.5)$, voor 'reproductiegericht' 3.1 $(\mathrm{SD} \pm 0.4)$, voor 'betekenisgericht' 3.6 $(\mathrm{SD} \pm 0.4)$ en voor 'toepassingsgericht' 3.8 $(\mathrm{SD} \pm 0.4)$.

\section{Correlaties}

De Pearson correlatiecoëfficiënten voor de verschillende leerstijlkenmerken zijn vermeld in tabel 2. Voor de leerstijlkenmerken 'ongericht' en 'toepassingsgericht' zijn significante correlaties gevonden, respectievelijk -0.36 en 0.19 .

Tabel 2. Pearson correlatiecoëfficiënten tussen de vier leerstijlkenmerken en het individuele aanwezigheidspercentage.

\begin{tabular}{lc}
\hline Leerstijlkenmerk & $\begin{array}{l}\text { Aanwezigheidspercen- } \\
\text { tage }\end{array}$ \\
\hline Ongericht & $-0.36^{*}$ \\
Reproductiegericht & -0.08 \\
Betekenisgericht & 0.17 \\
Toepassingsgericht & $0.19^{*}$ \\
\hline
\end{tabular}

De getallen met een ${ }^{*}$ zijn significant $(p<0.001)$.

\section{Beschouwing}

In dit retrospectieve onderzoek zijn voor twee leerstijlkenmerken (ongericht en toepassingsgericht) verbanden gevonden met de aanwezigheid bij het vaardigheidsonderwijs. Omdat er geen leervragenlijst bestond specifiek voor probleemgeoriënteerd onderwijs (PGO) is voor dit onderzoek een nieuwe vragenlijst samengesteld. Voor de validatie van deze vragenlijst is gebruik gemaakt van de kennis van de Nederlandse leerstijlexperts Vermunt, Vermetten en Van Luijk. Een kanttekening bij 
deze procedure is dat er uiteindelijk 76 van de oorspronkelijke 128 stellingen (59\%) konden worden gebruikt in de analyse. Het is voor te stellen dat als er meer stellingen in de analyse meegenomen zouden zijn dat onze resultaten zouden kunnen veranderen, waardoor gevonden resultaten sterker of zwakker zouden kunnen worden. Echter, wij hebben besloten om bij onvolledige consensus een stelling niet mee te nemen, daar deze ook toegeschreven kan worden aan een ander leerstijlkenmerk.

De andere variabele in dit onderzoek was de aanwezigheid. Er zijn verbanden aangetoond voor twee van de vier leerstijlkenmerken. Zo waren er significante correlaties voor de leerstijlkenmerken 'ongericht' (-0.36) en 'toepassingsgericht' (0.19). De andere twee leerstijlkenmerken 'betekenisgericht' en 'reproductiegericht' waren beide niet significant gecorreleerd, respectievelijk (0.17) en (-0.08).

De vraag is wat deze resultaten te betekenen hebben voor de onderwijspraktijk. De significante negatieve correlatie met betrekking tot het leerstijlkenmerk 'ongericht' betekent dat wanneer de aanwezigheid van de individuele student laag is, dit gepaard gaat met een hogere score op het leerstijlkenmerk 'ongericht'. Dit is op zich te verklaren als wij kijken naar de kenmerken van dit leerstijlkenmerk (tabel 1). Dit zijn studenten die moeilijk kunnen structureren en in hun leren sterk gericht zijn op externe sturing. Kortom, zij zijn dus erg afhankelijk, laten zich makkelijk leiden in hun keuzes en hebben niet veel regelmaat in hun studeren. Een sterk afwisselende aanwezigheid is voor te stellen bij deze studenten. Het onderwijs zou hier op in kunnen spelen door de trainingen voor hen veel gestructureerder aan te bieden. Ook zou studenten veel duidelijker gemaakt kunnen worden wat het effect van hun leer- stijl is, zodat zij die mogelijk aan gaan passen.

De significante positieve correlatie heeft betrekking op het leerstijlkenmerk 'toepassingsgericht'. Dat wil zeggen dat studenten die vaker aanwezig zijn, meer toepassingsgerichte leerstijlkenmerken hebben dan studenten die minder vaak deelnemen. Dit zijn studenten die meer nadenken over hun studie en een voorkeur hebben binnen hun studie voor praktisch toepasbare zaken. Zij zijn met andere woorden doelgericht. Dus door veel trainingen bij te wonen waar de theoretische kennis gekoppeld wordt aan vaardigheden (praktijk), vergroten zij de voor hen zo interessante en belangrijke kennis.

Een andere beperking van deze studie is dat we maar één jaargroep bekeken hebben. Er zou gekeken moeten worden of de gevonden resultaten reproduceerbaar zijn bij de andere jaargroepen. Ook zou een groep longitudinaal gedurende hun hele studie gevolgd moeten worden om op die manier te kunnen bevestigen of te weerleggen dat studentkenmerken veranderen gedurende de studie, zoals door Van Bokhoven verondersteld wordt.

\section{Concluderend}

Er zijn in deze studie aanwijzingen gevonden voor een samenhang tussen leerstijlkenmerken van studenten en deelname aan onderwijsactiviteiten. Een voorkeur voor 'ongericht' leren gaat samen met een relatief lage deelname en een voorkeur voor 'toepassingsgericht' leren met een relatief hoge deelname. Studentkenmerken gaan dus wel samen met wel of geen deelname aan onderwijsactiviteiten, maar hoeven nog niet de oorzaak te zijn. Voorlichting aan studenten over hun leerstijl zou inzicht kunnen geven in hun manier van studeren en hen mogelijkheden kunnen aanreiken om hun leerstijl te optimaliseren. 


\section{Dankbetuiging}

Graag willen de auteurs prof. dr. Vermunt en dr. Vermetten bedanken voor hun inbreng bij het valideren van de vragenlijst.

\section{Literatuur}

1. Caldas SJ. Reexamination of input and process factor effects on public school achievement. The Journal of Education Research 1993;86:206-14.

2. Simons PRJ. Leerlingkenmerken. In: Lowijck J, Verloop N, Onderwijskunde (ed.). Een kennisbasis voor professionals. Groningen: WoltersNoordhof; 1995. p. 1-40.

3. Scherpbier AJJA, Gerwen ALEM van, Bour EM, Vleuten CPM van der, Luijk SJ van. Aanwezigheid bij laboratoriumtrainingen en de prestaties op de vaardigheidstoets. Bulletin Medisch Onderwijs 1994;18(1):17-28.

4. Scherpbier AJJA, Kerckhofs E, Verhoeven BH, Gerwen ALEM van, Wolfhagen HAP, Vleuten CPM van der. Trends in de aanwezigheid bij het vaardigheidsonderwijs. Bulletin Medisch Onderwijs 1998;17(4):143-8.

5. Scherpbier AJJA, Verhoeven BH, Mameren $\mathrm{H}$ van, Kerkhofs E, Hoogenboom RJI, Vleuten CPM van der. Aanwezigheid en toetsprestaties: een exploratieve studie. Bulletin Medisch Onderwijs 1999;18(1):17-28.

6. Bokhoven MA van, Verhoeven BH, Scherpbier AJJA, Kerkhofs E, Gerwen ALEM van, Luijk SJ van, Vleuten CPM van der. De relatie tussen aanwezigheid tijdens vaardigheidstrainingen en studieresultaten: een cohortstudie. Bulletin Medisch Onderwijs 1999;18(2):66-73.

7. Luijk SJ. Vragenlijst leerstijlen voor probleemgestuurd onderwijs, interne rapportage evaluatieproject geneeskunde, 1998.

8. Vermunt J. Leerstijlen en sturen van leerprocessen in het hoger onderwijs: naar procesgerichte instructie in zelfstandig denken [proefschrift]. Amsterdam: Swets \& Zeitlinger; 1992.

\section{De auteurs:}

Drs. R.J. Nijenhuis is vijfdejaars geneeskundestudent en student-assistent, Skillslab.

Dr. A. Muijtjens is universitair docent, Capaciteitsgroep Onderwijsontwikkeling en Onderwijsresearch.

Dr. S.J. van Luijk is universitair docent, Capaciteitsgroep Onderwijsontwikkeling en Onderwijsresearch.

Drs. G.M. Verwijnen is arts en hoofd van het Skillslab.

Dr. J.J. Rethans is huisart en universitair hoofddocent, Skillslab.

Allen zijn verbonden aan de Faculteit der Geneeskunde van de Universiteit Maastricht.

Correspondentieadres:

Drs. R.J. Nijenhuis, Heugemerweg 35a, 6221 GE Maastricht, tel: 043-387 4907, fax: 043-387 6909, RJ.Nijenhuis@student.unimaas.nl.

\section{Summary}

Introduction: At Maastricht Medical School students acquire clinical skills (history taking, physical examination and communication skills) through voluntary sessions at the Skillslab. Attendance rates differ considerably among individual students (0-100\%). Several explanations of this phenomenon have been proposed, including the influence of the learning environment. Research has shown that more factors are involved. Learning styles may be one of them, but so far this has not been investigated. The aim of this study was to determine the relationship between attendance of training sessions and learning style.

Methods: Attendance figures were obtained from the Skillslab attendance registration. In order to gain insight into the different learning styles, we surveyed third year medical students using a questionnaire, which consisted of 128 statements concerning characteristics of four learning styles (undirected, reproduction directed, meaning directed and application directed). Students were each characterised by a profile based on the percentages of these learning styles. In order to evaluate the relationship between attendance rate and learning style, Pearson correlation coefficients were calculated.

Results: In all 123 students were included. The median attendance was $75.2 \%$. We found a significant relation of $-0.36(p<0.01)$ for the 'undirected' learning style. Also the 'application directed' learning style was significantly correlated, $0.19(p<0.01)$. No significant correlation was demonstrated for the other two learning styles. Conclusions: The shown correlations point out that learning styles might contribute in explaning the differences in attendance. (Nijenhuis RJ, Muijtjens A, Luijk SJ van, Verwijnen GM, Rethans JJ. The relationship between between learning styles and attendance of training sessions by students. Dutch Journal of Medical Education 2003;22(6): 283-288.) 